\title{
Pain, CTCAE
}

National Cancer Institute

\section{Source}

National Cancer Institute. Pain, CT CAE. NCI Thesaurus. Code C143725.

A disorder characterized by the sensation of marked discomfort, distress or agony. 